\title{
Evidence of response to unintentional selection for faster development and inbreeding depression in Crassostrea gigas larvae
}

\author{
Nicolas Taris ${ }^{a}$, Frederico M. Batista ${ }^{\mathrm{b}, \mathrm{c}}$ and Pierre Boudry ${ }^{\mathrm{a},}$
}

\author{
a Institut Français de Recherche pour l'Exploitation de la Mer (IFREMER), Laboratoire de Génétique et Pathologie \\ (LGP), 17390, La Tremblade, France

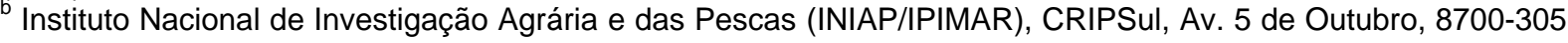 \\ Olhão, Portugal \\ c Instituto de Ciências Biomédicas Abel Salazar (ICBAS), Universidade do Porto, Largo Prof. Abel Salazar, 2 , \\ 4099-003 Porto, Portugal
}

*: Corresponding author : Pierre Boudry, email address : Pierre.Boudry@ifremer.fr

\begin{abstract}
:
Underlying consequences of domestication and artificial selection still remain largely unexplored in most aquacultured species. For species with a two phase life cycle, including the Pacific oyster Crassostrea gigas, most genetic studies have focused on the post-metamorphosis juvenile and adult stages, but relatively few considered the larval stage. To assess the consequence of hatchery practices on larval characters, especially growth, we performed a phenotypic study on larval progenies derived from crosses between Pacific oysters from natural beds and farmed Pacific oysters selected for desirable production traits such as rapid growth, for over seven generations. A set of three microsatellite loci was used to compare the genetic variability between the two parental broodstocks and to establish the relatedness between pairs of individuals within each broodstock. The mean relatedness of the hatchery broodstock was significantly different from expectations under the hypothesis of random association (i.e. no relatedness). On one hand, our results show a lower survival performance in the hatchery broodstock, which is associated with a multimodal distribution of growth rates. On the other hand, the hatchery broodstock had a higher proportion of success at metamorphosis. The results suggest that these larvae suffered from inbreeding depression, but that this was offset by better metamorphosis success. The combined effects are likely the result of unintentional selection for faster development in the hatchery through the practice of culling slow growing larvae and a concomitant reduction in the effective population size leading to inbreeding depression.
\end{abstract}

Keywords: Larval stage; Domestication; Selection; Inbreeding depression; Crassostrea gigas 


\section{Introduction}

As pointed out by Darwin (1883), domestic animals were initially modified through unconscious selection, and population means were altered across generations by the selection of superior individuals for breeding. Therefore, domestication is commonly viewed as a continuing process by which humans, trying to achieve certain goals, modify traits they find desirable (Siegel 1993). According to Hale (1969), domestication may be globally defined "as that condition wherein the breeding, care and feeding of animals is more or less controlled by man".

Compared to the knowledge of terrestrial vertebrates, most aquatic species are very close to their wild progenitors, and thus either virtually undomesticated or at the very early stages of domestication (Mignon-Grasteau et al. 2005). For species of aquacultural interest, domestication currently consists largely of the development of reliable rearing methods that set the stage for control of the life cycle and subsequent genetic improvement through selective breeding (Vandeputte and Launey 2004). However, this emphasis on the technical aspects of husbandry and propagation does not preclude genetic change resulting from intentional or unintentional selective processes and adaptation to culture conditions.

In some species, however, these technologies have matured to the point where selective breeding programs have been implemented for the genetic improvement of fish and shellfish species (e.g. Gjerde 1986; Gjedrem 1997; Knibb 2000; Davis and Hetzel 2000; Hulata 2001; Langdon et al. 2003). Through selection on traits such as growth and disease resistance, selective breeding programs logically aim at producing healthy seedstock with improved production performance (Keys et al. 2004). Selective programs can also aim at narrowing the variance of traits so that all individuals perform similarly (i.e. canalization). Unintentional side effects affecting other traits can arise by indirect selection, through genetic correlations 
between target and non-target traits (Pascual et al. 2004) or genetic drift in small breeding populations (Hedgecock and Sly 1990; Gaffney et al. 1992). In aquatic species, these indirect responses to selection are all the more important because genetic variance is typically high, usually due to a life cycle characterized by high fecundity, large population sizes and external fertilization with broadcast spawning. Furthermore, cultured populations are sometimes established using few breeders and have small genetically-effective population sizes promoting genetic drift (Allendorf et al. 1987). These small effective population sizes also lead to increased homozygosity and to chance mating between relatives even if mating is random and this can reduce fitness-connected traits, through inbreeding depression (Charlesworth and Charlesworth 1987; Falconer and Mackay 1996). The rapid accumulation of inbreeding seems to result frequently in the degradation of hatchery-propagated breeding stocks (Bentsen and Olesen 2002).

In contrast to fin fish (Busack and Currens 1995; Roberge et al. 2006), little is known about intentional and unintentional consequences of domestication of bivalves from a genetic point of view. For these species, the life cycle includes a critical larval phase (Pechenik 1999). Studies of selection in bivalves have focused on juvenile and adult development stages, but relatively few give consideration to the larval stage (Lannan 1972, 1980; Hedgecock et al. 1995, 1996; Pace et al. 2006).

In many cultured bivalve species, mortality is high in the larval phase making it most likely to be affected by artificial rearing conditions, and domestication selection, since the later stages are usually grown under more natural conditions (i.e. tidal and coastal areas). Selection of fast growing larvae, by discarding smallest growing larvae (i.e. culling) is a common practice in shellfish hatcheries (Loosanoff and Davis 1963; Lipovsky 1984). This practice is of interest to producers because it reduces the time to metamorphosis and its variability, but it can also contribute to a loss of genetic diversity in cultured populations (Taris et al. 2006). 
Many studies tackled the heritability for larval growth in marine shellfish (Haley et al. 1975; Longwell 1976; Newkirk et al. 1977; Losee 1978; Newkirk 1980; Jones et al. 1996; Ernande et al. 2003; Dégremont 2003). Even if growth is generally considered as a trait with low to moderate heritability (Toro and Newkirk 1990), the majority of studies quoted above support the hypothesis that larval growth could respond to selection. However no studies have confirmed this point, especially when considering the combined influence of selection and inbreeding depression in populations with small effective sizes.

Here we report an experiment on the Pacific oyster Crassostrea gigas, the most widely cultured shellfish species worldwide, for which the hatchery-based production is important and in continuous progress (Goulletquer 2005). Aiming at obtaining a deeper insight to selective process related to the domestication of this species, we studied progenies of parental oysters originating from natural beds and others resulting from seven generations of hatchery domestication and selection for growth at juvenile and adult stages. We studied the development of larvae resulting from these different crosses by measuring larval growth, survival and settlement success. Concurrently, a set of three microsatellite loci using a PCRmultiplex technique was used to compare genetic variability between the two parental populations and to establish the relatedness between pairs of individuals within each population. Hence, our experiment aimed at studying how several generations of propagation in commercial hatcheries influences the evolution of larval traits through selection and/or inbreeding. 


\section{Material \& Methods}

Parental oysters

Two groups of parental oysters were used in the study: the first one $(n=47)$ was sampled from a natural bed in Charente-Maritime (France), the second one $(n=37)$ was sampled from one of the broodstock populations of the commercial hatchery Grainocéan (CharenteMaritime, France). This broodstock results from seven generations of closed hatchery matings. This population was subjected to individual-level selection to improve growth performance at juvenile and adult stages, and also subjected to the typical hatchery practice of culling larval cultures.

\section{Crosses}

Crosses were performed within and between the two types of parental oysters. These crosses produced four progenies: two within-strain crosses (females $\mathrm{W}$ x males $\mathrm{W}$ and females $\mathrm{H} \mathrm{x}$ males $\mathrm{H}$ ) and two reciprocal hybrid crosses (females $\mathrm{W}$ x males $\mathrm{H}$ and females $\mathrm{H}$ x males $\mathrm{W}$ ) where "H” stands for "Hatchery" and "W" for "Wild".

For each parental broodstock, spermatozoids from all males were collected by stripping the gonad and pooled. Using the same procedure, oocytes were pooled for each broodstock. For the hatchery broodstock, gametes from 17 males and 20 females were collected. The wild broodstock was composed of 14 males and 33 females. Gamete concentrations were estimated using Thoma and Malassez slides coupled to the SAMBA ${ }^{\mathrm{TM}}$ IPS image processing software for both spermatozoids and oocytes. Fertilization was performed at a ratio of 100 spermatozoa per oocyte, $10^{6}$ oocytes being used for each of the four matings. Three hours post-fertilization, embryos from each cross were transferred to three rearing tanks $\left(5 \times 10^{6}\right.$ embryos /tank; 3 replicated tanks/condition).

Gill fragments were individually sampled and preserved in ethanol for all parental oysters for further DNA analyses as described in Taris et al. (2005). 


\section{Larval rearing}

Larvae were reared in 30-l tanks filled with $1 \mu \mathrm{m}$ filtered sea water (temperature $24{ }^{\circ} \mathrm{C}$, salinity 28-30\%o) and were fed a standard diet, consisting of a mixture of Isochrysis aff. galbana (T-iso) and Chaetoceros gracilis according to a three-phase rationing (Taris et al.,

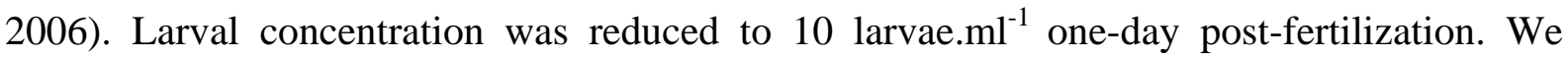
estimated the number of larvae in each tank by counting 5 water samples according to the procedure described in Utting and Spencer (1991). Two hundred larvae from each tank were also collected to measure their maximum shell length using the image processing system (SAMBA TM IPS 4.40, Samba Technologies). The larval size measurements were performed every 2-3 days. When the first pediveliger larvae (i.e. ready-to-settle larvae) were observed, the largest larvae were retained by sieving on a 220 - $\mu$ m mesh (i.e. height greater than 280 $\mu \mathrm{m})$ and transferred to 220- $\mu \mathrm{m}$ mesh-bottomed raceways with ground oyster shell. The remaining larvae were returned to the larval rearing tanks. This procedure was performed every two days. We estimated settlement success as the ratio of the number of successfully metamorphosed juveniles to the number of pediveliger larvae put into the settlement raceways for each progeny 10 days post-settlement. Three estimates of the number of juveniles (= total weight of a cohort / mean individual weight) were calculated for each cross and each settlement cohort.

DNA analyses

Genetic polymorphism was estimated for individuals from both the hatchery population and wild population using a set of three microsatellite loci (CG49 and CG108 from Magoulas et al. 1998; L10 from Huvet et al. 2000) in multiplex PCR conditions as described in Taris et al. (2005). Number of alleles, observed heterozygosity (Ho) and expected heterozygosity (He) (Nei 1987) per locus within population were determined by using GENETIX 4.05 (Belkhir et al. 2004). Deviation from Hardy-Weinberg expectations was estimated in each population within 
locus by using $f$, the Weir and Cockerham's (1984) estimator of Fis. Significance levels were tested using the permutation procedures available in GENETIX. Allelic richness was also determined to make direct comparisons of the mean number of alleles among populations irrespective of sample size (Fstat program; Goudet 1995). In addition, the frequency of null alleles was estimated per locus. The method used was based on the maximum likelihood approach developed by Kalinowski and Taper (2006), implemented in ML-RELATE (Kalinowski et al., 2006).

\section{Pairwise relatedness coefficient}

For both broodstocks, we estimated the relatedness between all potential pair of parents using Queller and Goodnight (rxyQG) (Queller and Goodnight 1989) and Lynch and Ritland (rxyLR) (Lynch and Ritland 1999) coefficients, which use population-level allele frequencies to determine the probability that two individuals share alleles that are identical by descent using the program IDENTIX (Belkhir et al. 2002). To evaluate the patterns of relatedness, a Monte Carlo resampling procedure implemented in IDENTIX was also used with 1000 permutations in order to compare the observed distribution of $\mathrm{r}$ with that expected under the null hypothesis of no relatedness. In parallel, a second program (ML-RELATE, Kalinowski et al., 2006), accommodating null alleles, was used. ML-RELATE relies on likelihood calculations (Wagner et al. 2006) to estimate relatedness (rxy ML).

Phenotypic data analysis

Larval size-frequency distributions were examined through modal analysis. Initially the distributions were plotted using size class intervals of $10 \mu \mathrm{m}$. This interval was chosen since it was larger than the error of measurements and minimized the number of adjacent empty classes. The size-frequency histograms were smoothed using a weighted moving average at the third order to rule out spurious peaks (Frontier and Pichod Viale 1991). We performed the modal analysis using a combination of Bhattacharya's method (Bhattacharya 1967) and 
NORMSEP (Hasselblad 1966) to decompose complex size-frequency distributions into a series of best-fit normal curves. Bhattacharya's method was used to first obtain an initial number of modes and their approximate means. The NORMSEP method (for SEParation of the NORMally) allowed refining the results using maximum likelihood approaches. We used Fisat (2002) for examination of this modal analysis. We tested for normality by means of the Kolmogorov-Smirnov goodness-of-fit test.

The coefficient of variation for larval length was analyzed for significant differences between crosses at each sampling date using a non-parametric procedure (Kruskal-Wallis test, PROC NPAR1WAY, SAS/STAT ${ }^{\circledR}$ Software, SAS Institute Inc. 1999). Survival was calculated as the ratio between the number of larvae at day 3 and day 20 and analyzed as Poisson data using a log link function (SAS macro GLIMMIX; Littell et al. 1996). This link function was used to model responses since the dependent variable is assumed to be nonlinearly (Poisson distribution) related to the predictors, such as Log link: $\mathrm{f}(\mathrm{z})=\log (\mathrm{z})$; McCullagh and Nelder 1989). For this purpose, we used the following model:

$$
Y_{i j}=\mu+\text { cross }_{i}+\operatorname{rep}_{j}+\varepsilon_{i j}
$$

where $Y_{i j}$ is the dependant variable, $\mu$ is the overall mean, rep ${ }_{j}$ is the random replicate effect nested within crosses $(j=1-3)$, cross is the effect of the 4 experimental crosses $(i=1-4)$ and cij is the residual error. Significance tests were based on F statistics for fixed effects (= cross effect), whereas tests for random effects (= replicate effect) were based on likelihood ratios between sub-models, which asymptotically follow a chi-squared distribution (Self and Liang 1987).

\section{Results}

\section{Genetic analysis of parental oysters}

Population-level diversity (Table 1). The allelic richness in the hatchery broodstock ranged from 9 to 13 per locus. In the wild broodstock, we observed an average of 31.3 alleles 
corresponding to a mean reduction of allelic diversity of about $68 \%$ for the hatchery broodstock (from 49.9 to $76.2 \%$ per locus). Regarding both observed and expected heterozygosity estimates, we found systematically higher values for the population from natural environment (superior to 0.80 versus 0.66 for Ho, 0.96 in multilocus analysis versus 0.77 for He). Considering Fis estimates for each locus, significant positive values, indicative of heterozygote deficiencies, were observed in both populations, except for the hatchery broodstock at locus Cg108.

\section{Relatedness coefficients.}

Pairwise relatedness (r) values for both Queller and Goodnight (rxyQG) and Lynch and Ritland (rxyLR) estimators were calculated among individuals within each parental population. The permutation tests using relatedness values supported the presence of kin structure within hatchery broodstock. The mean pairwise coefficient (both rxy LR and rxy QG) is significantly distinguishable from its expected distribution under hypothesis of random association (i.e. no relatedness) (Figure $1 ; \mathrm{P}=0.004$ and $\mathrm{P}=0.008$ respectively). On the contrary for the wild parental population, no significant departure from the expected distribution was observed (Figure $1 ; \mathrm{P}=0.573$ and $\mathrm{P}=0.134$ ). The (r) values obtained from likelihood calculations (rxyML), accommodating for null alleles, are also distinguishable between populations ( $\mathrm{r}=0.13$ for hatchery broodstock; $\mathrm{r}=0.05$ for the wild broodstock). 
Phenotypic analysis of larval oyster

Size distribution over time. The larval length-frequency distribution of each progeny varied over time from hatching to the ready-to-settlement stage. To avoid the inevitable bias related to differences in larval density (due to different fertilization and survival rates between crosses, see below), we only present in Figure 2 the replicates showing, for the four progenies, a similar larval density at day 3 (380 000, 394 400, 388 800, 395600 for H x H, H x W, W x $\mathrm{H}$ and $\mathrm{W} \mathrm{x} \mathrm{W}$ respectively).

Tests for normality using the Kolmogorov-Smirnov goodness-of-fit test showed strong evidence of deviation $(\mathrm{P}<0.05)$ for the $\mathrm{H} \times \mathrm{H}$ replicate and this from day 10 postfertilization. This was supported by the use of the Fisat software that decomposes complex size-frequency distributions into a series of best-fit normal curves. Values of modal decomposition are shown in Table 2. The $\mathrm{H} \mathrm{x} \mathrm{H}$ progeny stood apart from the others, clearly showing a multimodal distribution as early as day 10 post-fertilization. This multimodality was more distinctly observed three days after fertilization (modal components represented respectively $28 \%$ and $72 \%$ of the total effective). At the same sampling dates, the three other crosses showed an almost exclusive unimodal curve. From day 10 to 20 post-fertilization, a polymodal structure was confirmed for the $\mathrm{H}$ x $\mathrm{H}$ progeny. The histograms reveal two markedly different peaks in the size distribution. A first peak represents larval size ranging from 110 to $175 \mu \mathrm{m}$ (32 \% of the total effective). From day 10 to 17 post-fertilization, the growth rate of this group was virtually zero. The second represents a cohort of faster growing larvae (68 \% of the population at day 20) having a daily growth rate of $15 \mu \mathrm{m}$ (from day 10 to 17 post-fertilization). To a smaller degree, a bimodal distribution was also observed for the W x W progeny at days 15 to 17 post-fertilization. Finally, the hybrid modes showed intermediate values 17 days post-fertilization, ranged between the bigger modes from the $\mathrm{H} \mathrm{x}$ $\mathrm{H}$ and $\mathrm{W} x \mathrm{~W}$ progenies. 
Temporal changes in the coefficient of variation for larval length. In relation to the lengthfrequency distribution previously described, the temporal changes in the coefficient of variation of mean larval length varied among crosses (Figure 3). The $\mathrm{H} \mathrm{x} \mathrm{H}$ progeny were more variable than three others crosses as early as day 8 post-fertilization $\left(\chi^{2}=9.36, \mathrm{P}=\right.$ 0.02). ANOVAs performed at further dates showed that the coefficient of variation of larval length differed significantly between progenies. The coefficient of variation of the $\mathrm{H} \times \mathrm{H}$ larvae reached a maximum of $22.63 \%$ at day 17 post-fertilization, resulting from a progressive increase. The $\mathrm{W} \times \mathrm{W}$ progeny ended the larval period with a lower value $(\mathrm{CV}=$ $15.37 \%$ ) but intermediate coefficient of variation compared to the values of the two hybrids progenies $(\mathrm{CV}=12.69 \%(\mathrm{H} \times \mathrm{W}) ; \mathrm{CV}=12.19 \%(\mathrm{~W} \times \mathrm{H}))$.

Survival.

Mean survival of larvae from day 3 to day 20 for each cross type is illustrated in Figure 4. No significant survival was observed between crosses up to day $17 . \mathrm{H} \times \mathrm{H}$ progeny showed significantly lower survival than the other progenies from day 17. Even though the $\mathrm{W} \times \mathrm{W}$ larvae had the best mean percentage survival of all crosses, it was not significantly different from the two hybrids.

Settlement timing and success. For all progenies, the settlement lasted 12 days (from day 20 to 32 post-fertilization as reported on the figure 5 where the effectives were pooled by interval of two days, hence starting from day 22). For the $\mathrm{H} x \mathrm{H}$ progeny, $50.04 \pm 12.78 \%$ of pediveliger larvae were present in the two first days of pediveliger collection and $78.52 \pm 9.5 \%$ after four days. After this, we observed few residual larvae. In contrast, the temporal distribution of the effective of pediveliger larvae were bell-shaped for the three others progenies $(17.22 \pm 12.42$ \% ( $\mathrm{H} \times \mathrm{W}), 2.89 \pm 3.58 \%(\mathrm{~W} \times \mathrm{H}), 24.11 \pm 16.83 \%(\mathrm{~W} \times \mathrm{W})$ for the first two days of collection). Furthermore, the results of global assessment for settlement success was respectively $90.7 \% \mathrm{H}$ x H, $72.3 \% \mathrm{~W}$ x W, $78.1 \% \mathrm{H} \mathrm{x} \mathrm{W}$ and $68.7 \% \mathrm{~W}$ x H. 


\section{Discussion}

Despite the potential importance of processes acting at early development stages, relatively few studies have focused on the evolution of larval traits due to domestication-related selective pressures. Some studies dealt with the life history of Crassostrea gigas (Ernande et al. 2003) but did not tackle the question of the consequences of selection for growth in hatcheries, where genetic drift has also been reported (Hedgecock and Sly 1990; Hedgecock et al. 1992).

Our experiment, describing phenotypic patterns for larval traits in crosses with a known history of selection and data for the genetic relatedness of the parental oysters allows us to discuss some interesting trends and patterns.

\section{Larval phenotypic trends}

First, based on the larval size-frequency histograms, we observed two different patterns according to the origin of the progeny. These patterns are confirmed by the temporal changes of the coefficient of variation of larval size. The $\mathrm{H} \times \mathrm{H}$ progeny is different from the three others from day 8 post-fertilization. This clearly reflects important variability in the size distribution for this progeny that is not present in the other groups. At day 10 postfertilization, a bimodal component can be observed whereas the three other progenies showed unimodal distributions. With time, this apparent distinction became more defined until it formed two distinct groups at day 15 and 17 post-fertilization that seem to correspond objectively to slow and fast growing larvae. Interestingly, the $\mathrm{W}$ x $\mathrm{W}$ progeny also presented a bimodal distribution at day 15 and 17 post-fertilization, while our two outbred progenies did not. This supports the hypothesis that inbreeding depression could be a driving evolutionary force in wild oyster populations (Hedgecock et al., in press). More microsatellite markers 
would be needed to detect significant relatedness in our $\mathrm{W}$ sample and validate this hypothesis.

The second trend can be observed through both values of survival and settlement success. The mean percentage of survival at days 17 and 20 (i.e. just before the first days of settlement) distinguished the $\mathrm{H}$ x $\mathrm{H}$ progeny from all others progenies. Only $41.6 \%$ of the whole larvae population survived to this date. However, this relatively smaller proportion of larvae settled within a 3-day period with a high rate of settlement success of $90.7 \%$. It might be deduced that the group of slow growing larvae (size ranged from 110 to $175 \mu \mathrm{m}$ ) that produced the second mode in the size distribution in this cross died before reaching metamorphosis. This is supported by the temporal distribution of pediveliger larvae, which should exhibit an increase at the end of the period if these smaller animals had survived because they would be expected to produce a second wave of pediveliger larvae. Our data, however, indicate that only the portion of 'fast growing' larvae appear in the settling $\mathrm{H} \mathrm{x} \mathrm{H}$ population.

Significance of larval trends: inbreeding depression versus response to selection?

We favor the hypothesis that inbreeding depression explains this 'slow' growing (and finally dying) sub-population in only the $\mathrm{H} \times \mathrm{H}$ cross. Inbreeding depression has already been studied in bivalves, recording the performance in progenies of sib families or selfing hermaphrodites (with expected inbreeding coefficients $0.25<\mathrm{F}<0.5$ ). It was observed at the larval stage in Ostrea edulis (Bierne et al. 1998), Crassostrea virginica (Longwell and Stiles 1973), Pecten maximus (Beaumont and Budd 1994), Argopecten circularis (Ibarra et al. 1995), and Crassostrea gigas (Hedgecock et al. 1995; Launey and Hedgecock 2001). Launey and Hedgecock (2001) have clearly demonstrated the high load of deleterious mutations carried by C. gigas. The phenotypic trends observed in our study may result in the expression of this genetic load, resulting from the breeding of related individuals. 
The hatchery population exhibited mean values of rxy almost six times higher than the wild broodstock regarding both Queller and Goodnight and Lynch and Ritland coefficients and almost three times higher based on likelihood estimator. Oysters within this population are genetically more related than expected in a randomly mating population. This seemed to be sufficient to lead to the expression of inbreeding depression at larval stage. Inbreeding depression notably may arise because the inbreeding increases the probability that an individual homozygous for segregating recessive alleles (Lynch and Walsh 1998). Deleterious recessive effects are thought to be major cause of inbreeding depression (Charlesworth and Charlesworth 1999), and especially for C. gigas (Launey and Hedgecock 2001). Furthermore, under additive gene action, trait mean and variance of the hybrid progeny should be intermediate between those of the "pure” lines (Lynch and Walsh 1998). In our experiment, both hybrid lines did not present a multimodal size distribution (Figure 2), showed similar survival rates and time to settlement pattern than the $\mathrm{W} x \mathrm{~W}$ progeny (Figures 4 and 5) and expressed intermediate growth values. This supports the hypothesis of the recessive nature of the load of deleterious mutations carried by C. gigas, affecting only the inbred fraction of our $\mathrm{H}$ x H progeny.

Evans et al. (2004) found, after two growing seasons, significant inbreeding depression of yield and individual growth rate observed in families with a weak value inbreeding coefficient $\mathrm{F}=0.0625(\mathrm{P}<0.01)$. This study does not include the larval stage, but underlines the fact that inbreeding depression may be observed with low values of $\mathrm{F}$, knowing that inbreeding coefficient of an individual is equal to the relatedness coefficient of the two parents.

Conversely, in the $\mathrm{H} \times \mathrm{H}$ progeny, we also observed a group of fast growing larvae that exhibited the best percentage of settlement success. The mortality of 'slow' growing larvae might have lead to a reduced larval density in the rearing tanks from day 15, potentially explaining that the remaining larvae grew faster. However, this possible density effect did not 
equally affect all $\mathrm{H} \times \mathrm{H}$ larvae (see Table 2), supporting the hypothesis that our progenies might be genetically differed for their ability to grow and successfully settle.

In order to further investigate this response to selection for fast growing larvae, simulation based on the breeder's equation may be used. This equation describes the relationship between a response to selection for a given trait, the heritability of that trait, and the intensity of the selection applied, such as:

$$
\Delta \mu=h^{2} \mathrm{~S}
$$

where $\Delta \mu$ is the gain in the mean phenotype across generations, $\mathrm{S}$ is the selective pressure defined as the within-generation difference between the mean phenotype after an episode of selection (but before reproduction) and the mean before selection, and $h^{2}$ is the heritability (Lynch and Walsh 1998). If we consider a value of selective pressure of $20 \mu \mathrm{m}$ (a plausible value, considering the effect of culling, Taris et al. 2006), coupled with a heritability equal to 0.16 (Dégremont 2003), we obtain a gain of 3.2 $\mu$ m per generation. Knowing that our hatchery broodstock resulted from seven generations of closed hatchery mating, and assuming a constant selective pressure, the gain in size after seven generations should be approximately $20 \mu \mathrm{m}$. This fits well with the observed difference of about $20 \mu \mathrm{m}$ between the sub-population of fast growing $\mathrm{H} \mathrm{x} \mathrm{H}$ larvae and the highest modal mean of the $\mathrm{W} \times \mathrm{W}$ larvae. This, together with the intermediate position of the two hybrid progenies, supports the hypothesis that fast growing larvae could efficiently be selected for and thus supports the observed phenotypic trend in the present experiment.

Furthermore, this contrasting observation of inbreeding depression balanced with an effective response to selection is potentially avoided in hatcheries since the culling of slow growing larvae is commonly performed. Thus, by culling this part of the larval population, hatcheries might preserve a substantial diversity held by heterogezygous individuals. Paradoxically, culling could preserve fitness in hatcheries, at least on the short-term by eliminating the most 
inbred larvae.

Alternatively, it is difficult to exclude a correlated response at larval stage to selection at adult stage. The relative performance of our progenies at later stages is currently being investigated to further document their difference in growth performances. However, genetic correlations between larval and post-larval traits are usually low or absent (Ernande et al. 2003) supporting the hypothesis of a decoupling between life-stages in order to break fitness trade-offs between adaptations to different tasks (Moran 1994). This hypothesis is therefore unlikely to explain our results. Further studies are required to corroborate the hypothesis of effective selection for larval growth due to larval culling in hatcheries.

Phenotypic and genetic correlations between larval growth and settlement success.

In a quantitative genetic study of early life history traits in C. gigas, Ernande et al. (2003) observed negative genetic correlation between larval development rate and size at settlement, on the one hand, and metamorphosis success, on the other. They proposed that these correlations mean that fast developing genotypes settle and metamorphose early, but have a low survival probability during metamorphosis. They interpreted this as a possible cost of metamorphosing early. Our results do not support these results as the fast growing larvae of the $\mathrm{H} \times \mathrm{H}$ progeny showed the highest settlement success of our four tested progenies, showing that the negative genetic correlation observed by Ernande et al. (2003) may vary between genotypes or could be modified by selection. It should be noted that such a high settlement success $(90.7 \%)$ is rarely observed in the hatchery where the experiment was performed, where most experiments involve wild broodstock (Robert and Gérard 1999). More studies are needed to further document genetic correlations between pre- and postmetamorphic traits in C. gigas. 


\section{Conclusion}

411 Larval development of our $\mathrm{H}$ x $\mathrm{H}$ progeny might reveal two concomitant opposite effects:

412

413

414

415 first, expression of the genetic load in a significant portion of the population, and on the other side, response to selection of fast growing larvae, associated with a high metamorphosis success.

Further studies are required to validate this observation which appears to be essential in terms of conservation of genetic diversity for species under artificial selection. For this purpose, the genotyping of larvae (not only their parents) is needed to determine the heterozygosity among sub-populations and demonstrate the importance of genetic load and inbreeding depression at larval stage (Bierne et al., 1998; Launey and Hedgecock, 2001).

In hatcheries, larvae of C. gigas are size-selected by culling, affecting genetic diversity of the resulting population (Taris et al. 2006). Here we propose that differential selection, coupled with a presumed inbreeding effect, may co-occur in hatcheries. Culling can (1) lead to favor more heterozygous genotypes (expression of non-additive genetic variance), and (2) select for faster growing larvae as additive variance exist for that trait. Culling appears to make more complex the effect of culling when significant inbreeding is present in the population. The results reported here are one more step toward understanding the underlying consequences on artificial size-selection at larval stage and open new perspectives on the strategies that may be suggested for genetic management of bivalves in hatcheries. 


\section{Acknowledgements}

430

431

This work was partially funded by the BRG (Bureau des Ressources Génétiques), the Ministère de l’Ecologie et du Développement Durable (Convention n¹4-C/2003) and the Conseil Général of Charente-Maritime. The authors wish to thank the Ifremer hatchery team in La Tremblade for technical assistance during the larval and post-larval rearing and, more specially, Pascal Phelipot. We also are grateful to Grainocéan for providing the hatchery broodstock and to Mark Camara for useful comments and reading of this manuscript.

\section{References}

Allendorf, F.W., Ryman, N., Utter, F.M., 1987. Genetics and fishery management past, present, and future. In N. Ryman and F.M. Utter, (eds.) Population genetics and fishery management. Washington Sea Grant Program, Seattle, 1-19.

Beaumont, A.R., Budd, M.D., 1983. Effects of self-fertilization and other factors on the early development of the scallop Pecten maximus. Mar. Biol., 76: 285-289.

Belkhir, K., Castric, V., Bonhomme, F., 2002. IDENTIX, a software to test for relatedness in a population using permutation methods. Mol. Ecol. Notes, 2: 611-614.

Belkhir, K., Borsa, P., Chikhi, L., Raufaste, N., Bonhomme, F., 1996-2004. Genetix 4.05, logiciel sous Windows ${ }^{\mathrm{TM}}$ pour la génétique des populations. Laboratoire Génome, Populations, Interactions, CNRS UMR 5000, Université de Montpellier II, Montpellier (France). Available from http://www.genetix.univ-montp2.fr/genetix/genetix.htm 
Bentsen, H.B., Olesen, I., 2002. Designing aquaculture mass selection programs to avoid high inbreeding rates. Aquaculture, 204: 349-359.

Bhattacharya, C.G., 1967. A simple method of resolution of a distribution into Gaussian components. Biometrics, 23: 115-135.

Bierne, N., Launey; S., Naciri-Graven, Y., Bonhomme, F. 1998. Early effect of inbreeding as revealed by microsatellite analyses on Ostrea edulis larvae. Genetics, 148: 1893-1906.

Busack, C.A., Currens, K.P. 1995. Genetic risks and hazards in hatchery operations: fundamental concepts and issues. American Fisheries Society Symposium, 15: 71-80.

Charlesworth, D., Charlesworth, B., 1987. Inbreeding depression and its evolutionary consequences. Ann. Rev. Ecol. Syst., 18: 237-268.

Charlesworth, B., Charlesworth, D., 1999. The genetic basis of inbreeding depression. Genet. Res., 74: 329-340.

Darwin, C., 1883. The variation of animals and plants under domestication. 2 vols. 2nd (ed.) New York, D. Appleton \& Co. [first published London, John Murray, 1868].

Davis, G.P., Hetzel, D.J.S., 2000. Integrating molecular genetic technology with traditional approaches for genetic improvement in aquaculture species. Aquac. Res., 31: 3-10. 
484

Dégremont, L., 2003. Etude des bases génétiques de la mortalité estivale et des relations avec la croissance chez les juvéniles de l'huître creuse Crassostrea gigas. Thèse de Doctorat de l’Université de Caen. 333 p.

Ernande, B., Clobert, J., McCombie, H., Boudry, P., 2003. Genetic polymorphism and tradeoffs in the early life-history strategy of the Pacific oyster, Crassostrea gigas (Thunberg, 1795): A quantitative genetics study. J. Evolution. Biol., 16: 399-141.

Evans, F., Matson, S., Brake, J., Langdon, C., 2004. The effects of inbreeding on performance traits of adult Pacific oysters (Crassostrea gigas). Aquaculture, 230: 89-98.

Falconer, D.S., Mackay, T.F.C., 1996 Introduction to Quantitative Genetics. $4^{\text {th }}$ Edition. Pearson Education Ltd., Essex, England.

FiSAT (FAO-ICLARM Stock Assessment Tools), 2002. Gayanilo, F.C.Jr., Sparee, P., Pauly, D.: Food and Agriculture Organization of the united nations, Rome.

http://www.fao.org/fi/statist/fisoft/fisat/downloads.htm

Frontier, S., Pichod-Viale, D., 1991. Ecosystèmes, structure, fonctionnement, évolution. Masson.

Gaffney, P.M., Davis, C.V., Hawes, R.O., 1992. Assessment of drift and selection in hatchery populations of oysters (Crassostrea virginica). Aquaculture, 105: 1-20.

Gjerde, B., 1986. Growth and reproduction in fish and shellfish. Aquaculture, 57: 37-55. 
Gjedrem, T. 1997. Selective breeding to improve aquaculture production. World Aquac., 28: 33- 45.

505

(Version 2.9.3)

509

Hedgecock, D., Sly, F., 1990. Genetic drift and effective population sizes of hatchery propagated stocks of the Pacific oyster, Crassostrea gigas. Aquaculture, 88: 21-38.

Goulletquer, P., 2005. CABI Aquaculture Compendium. Chapter Culture aquatic animals species: C. gigas. CAB Publishers, 46p.

Haley, L.E., Newkirk, G.F., Waugh, D.W., Doyle, R.W. (1975) A report on the quantitative genetics of growth and survivorship of the American oyster, Crassostrea virginica under laboratory conditions. $10^{\text {th }}$ European symposium on Marine Biology, Ostend, Belgium, 1: 221-228.

Hale, E.B., 1969. Domestication and the evolution of behaviour. In: The behaviour of Domestic Animals, Hafez, E.S.E. (ed.). Baillere, Tindall and Cassel, London, pp. 22-42.

Hasselblad, V., 1966. Estimation of parameters for a mixture of normal distributions. Technometrics, 8: 431-444. 
Hedgecock, D., Chow, V., Waples, R.S., 1992. Effective population numbers of shellfish broodstocks estimated from temporal variance in allelic frequencies. Aquaculture, 108: 215232.

Hedgecock, D., McGoldrick, D.J., Bayne, B.L., 1995. Hybrid vigor in pacific oysters: an experimental approach using crosses among inbred lines. Aquaculture, 137: 285-298.

Hedgecock, D., McGoldrick, D.J., Manahan, D.T., Vavra, J., Appelmans, N., Bayne, B.L., 1996. Quantitative and molecular genetic analysis of heterosis in bivalve mollusks. J. Exp. Mar. Biol. Ecol., 203: 49-59.

Hulata, G., 2001. Genetic manipulations in aquaculture: a review of stock improvement by classical and modern technologies. Genetica, 111: 155-173.

Huvet, A., Boudry, P., Ohresser, M., Delsert, C., Bonhomme, F., 2000. Variable microsatellites in the Pacific oyster Crassostrea gigas and the other cupped oyster species. Animal Genetics, 31: 71-72.

Ibarra, A., Cruz, P., Romero, B.A., 1995. Effects of inbreeding on growth and survival of selffertilized catarina scallop larvae, Argopecten circularis. Aquaculture, 134: 37-47.

Jones, R., Bates, J.A., Innes, D.J., Thompson. R.J., 1996. Quantitative genetic analysis of growth in larval scallops (Placopecten magellanicus). Mar. Biol., 124: 671-677. 
Kalinowski, S.T., Taper, M.L., 2006. Maximum likelihood estimation of the frequency of null alleles at microsatellite loci. Conservation Genetics, 7: 991-995.

Kalinowski, S.T., Wagner, A.P., Taper, M.L., 2006. ML-Relate: a computer program for maximum likelihood estimation of relatedness and relationship. Molecular Ecology Notes, 6: 576-579.

Keys, S.J., Crocos, P.J., Burridge, C.Y., Coman, G.J., Davis, G.P., Preston, N.P. 2004. Comparative growth and survival of inbred and outbred Penaeus (marsupenaeus) japonicus, reared under controlled environment conditions: indications of inbreeding depression. Aquaculture, 241: 151-168.

Knibb, W., 2000. Genetic improvement of marine fish - which method for industry? Aquac. Res., 31: 11-23.

Langdon, C., Evans, F., Jacobson, D., Blouin, M. 2003. Yields of cultured Pacific oysters Crassostrea gigas Thunberg improved after one generation of selection. Aquaculture, 220: 227-244.

Lannan, J.E. 1972. Estimating heritability and predicting response to selection for the pacific oyster, Crassostrea gigas. Proceedings of the National Shellfisheries Association, 62-66.

Lannan, J.E., 1980. Broodstock management of Crassostrea gigas: I. Genetic and environmental variation in survival in the larval rearing system. Aquaculture, 21: 323-336. 
Launey, S., Hedgecock, D. 2001. High genetic load in the pacific oyster Crassostrea gigas. Genetics, 159: 255-262.

Lipovsky, V.P., 1984. Oyster egg development as related to larval production in a commercial hatchery. Aquaculture, 39: 229-235.

Littell, R.C., Milliken, G.A., Stroup, W.W., Wolfinger, R.D. 1996. SAS system for mixed models. SAS Inst., Cary, NC.

Longwell, A.C. 1976. Review of genetic and related studies on commercial oysters and other pelecypod mollusks. J. Fish. Res. Board Can., 33: 1100-1110.

Longwell, A.C., Stiles, S.S., 1973. Gamete cross incompatibility and inbreeding in the commercial American oyster, Crassostrea virginica Gmelin. Cytologia, 38: 521-533.

Loosanoff, V.L., Davis, H.C. 1963. Rearing of Bivalve mollusks. Adv. Mar. Biol., 1: 1-136.

Losee, E., 1978. Influence of heredity on larval and spat growth in Crassostrea gigas. Proceedings of the ninth annual meeting World Mariculture Society, Atlanta, Georgia: 101107.

Lynch, M., Walsh, B., 1998. Genetics and Analysis of quantitative Traits. Sinauer Associates, Sunderland, MA.

Lynch, M., Ritland, K., 1999. Estimation of pairwise relatedness with molecular markers. 
602

603

604

605

606

607

608

609

610

611

612

613

614

615

616

617

618

619

620

621

622

623

624

Genetics, 152: 1753-1766.

Magoulas, A., Gjetvaj, B., Terzoglou, V., Zouros, E., 1998. Three polymorphic microsatellites in the Japanese oyster Crassostrea gigas (Thunberg). Animal Genetics, 29: 6970.

Mignon-Grasteau, S., Boissy, A., Bouix, J., Faure, J., Fisher, A., Hinch, G., Jensen, P., Le Neindre, P., Mormède, P., Prunet, P., Vandeputte, M., Beaumont, C., 2005. Genetics of adaptation and domestication in livestock. Lives. Prod. Sci., 93: 3-14.

McCullagh, P., Nelder. J.A., 1989. Generalized Linear Models. Monographs on Statistics and Applied Probability No. 37. Chapman \& Hall, London.

Moran, N.A., 1994. Adaptation and constraint in the complex life cycles of animals. Annu. Rev. Ecol. Evol. S., 25: 573-600.

Nei, M., 1987. Molecular Evolutionary Genetics. Columbia University Press, New York.

Newkirk, G.F., 1980. Review of the genetics and the potential for selective breeding of commercially important bivalves. Aquaculture, 19: 209-228.

Newkirk, G.F., Haley, L.E., Waugh, D.L., Doyle, R., 1977. Genetics of larvae and spat growth rate in the oyster Crassostrea virginica. Mar. Biol., 41: 49-52. 
625

626

627

628

629

630

631

632

633

634

635

636

637

638

639

640

641

642

643

644

645

646

647

648

649

Pace, D.A., Marsh, A.G., Leong, P.K., Green, A.J., Hedgecock, D., Manahan, D.T. 2006.

Physiological bases of genetically determined variation in growth of marine invertebrate larvae: A study of growth heterosis in the bivalve Crassostrea gigas. J. Exp. Mar. Biol. Ecol., 335: 188-209.

Pascual, C., Arena, L., Cuzon, G., Gaxiola, G., Taboada, G., Valenzuela, M., Rosas, C., 2004. Effect of a size-based selection program on blood metabolites and immune response of Litopenaeus vannamei juveniles fed different dietary carbohydrate levels. Aquaculture, 230: 405-416.

Pechenik, J.A., 1999. On the advantages and disadvantages of larval stages in benthic marine invertebrate life cycles. Mar. Ecol.-Prog. Ser., 177: 269-297.

Queller, D.C., Goodnight, K.F., 1989. Estimating relatedness using genetic markers. Evolution, 43: 258-275.

Roberge, C., Einum, S., Guderley, H., Bernatchez, L., 2006. Rapid parallel evolutionary changes of gene transcription profiles in farmed Atlantic salmon. Mol. Ecol., 15: 9-20.

Robert, R., Gérard, A., 1999. Bivalve hatchery technology: the current situation for the Pacific oyster Crassostrea gigas and the scallop Pecten maximus in France. Aquat. Living Resour., 12: 121-130.

SAS Institute Inc., 1999. SAS/STAT User’s Guide, Version 8, Cary, NC: SAS Institute Inc. 
Self, S.G., Liang, K.Y., 1987. Asymptotic properties of maximum likelihood estimators and likelihood ratio tests under nonstandard conditions. J. Amer. Statist. Assoc., 82: 604-610.

Siegel, P.B., 1993. Opportunities for science and technology to improve production systems to assure animal well-being and economic viability. In: Proc. of Conference on Food Animal Well-Being. Purdue University Office of Agric. Res. Prog. W. Lafayette, IN. p.79- 88.

Taris, N., Baron, S., Sharbel, T.F., Sauvage, C., Boudry, P., 2005. A combined microsatellite multiplexing and boiling DNA extraction method for high throughput parentage analyses in the Pacific oyster (Crassostrea gigas). Aquac. Res., 36: 1-3.

Taris, N., Ernande, B., McCombie, H., Boudry, P., 2006. Phenotypic and genetic consequences of size selection at the larval stage in the Pacific oyster (Crassostrea gigas). J. Exp. Mar. Biol. Ecol., 333: 147-158.

Toro, J.E., Newkirk, G.F., 1990. Divergent selection for growth rate in the European oyster Ostrea edulis: response to selection and estimation of genetic parameters. Mar. Ecol-Prog. Ser., 62: 219-227.

Utting, S.D., Spencer, B.E., 1991. The hatchery culture of bivalve mollusc larvae and juveniles, Lab.-Leafl.-Dir.-Fish.-Res.-G.B. 68, 31p.

Vandeputte, M., Launey, S., 2004. Quelle gestion génétique de la domestication chez les poissons? INRA Productions Animales, 17: 237-242. 
675 Wagner, A.P., Creel, S., Kalinowski, S.T., 2006. Maximum likelihood estimation of 676 relatedness and relationship using microsatellite loci with null alleles. Heredity, 97: 336-345.

677

678 Weir, B.S., Cockerham, C.C., 1984. Estimating F-statistics for the analysis of population 679 structure. Evolution, 38: 1358-1370. 
Table 1: Genetic variability of parental populations at three microsatellite loci $(\mathrm{N}=$ sample size; $\mathrm{A}$ = number of allele (Allelic Richness for the wild population was determined per locus based on minimal sample size of 37 diploid individuals); $H o=$ observed heterozygosity; $H n b$ $=$ unbiased heterozygosity; Null allele freq. $=$ frequency of null alleles using maximum likelihood estimate; $F_{\text {is }}$ estimates according to Weir and Cockerham (1984). $F_{\text {is }}$ values are followed by a significance test based on 1000 permutations; (ns) corresponds to non significant values of $\mathrm{p}, *$ of $\mathrm{p}<0.05$ and $* * \mathrm{p}<0.001$ after Bonferroni correction on locus).

\begin{tabular}{|c|c|c|c|}
\hline \multirow[t]{2}{*}{ Locus } & \multirow[t]{2}{*}{ Parameter } & \multicolumn{2}{|c|}{ Populations } \\
\hline & & Hatchery & Wild \\
\hline \multirow{6}{*}{$\begin{array}{l}\text { Cg108 } \\
\end{array}$} & $\mathrm{N}$ & 37 & 46 \\
\hline & A & 9 & 37 (34.49) \\
\hline & $H_{o}$ & 0.59 & 0.89 \\
\hline & $H n b$ & 0.61 & 0.97 \\
\hline & Null allele freq. & 0 & 0.04 \\
\hline & $F_{\text {is }}$ & $0.03^{\mathrm{ns}}$ & $0.09^{* *}$ \\
\hline \multirow[t]{6}{*}{ L10 } & $\mathrm{N}$ & 37 & 47 \\
\hline & A & 8 & 37 (33.64) \\
\hline & $H_{o}$ & 0.65 & 0.89 \\
\hline & $H n b$ & 0.8 & 0.97 \\
\hline & Null allele freq. & 0.09 & 0.02 \\
\hline & $F_{\text {is }}$ & $0.19^{*}$ & $0.08^{*}$ \\
\hline \multirow[t]{6}{*}{ Cg49 } & $\mathrm{N}$ & 37 & 46 \\
\hline & A & 13 & 28 (25.99) \\
\hline & $H_{o}$ & 0.73 & 0.8 \\
\hline & $H n b$ & 0.91 & 0.94 \\
\hline & Null allele freq. & 0.09 & 0.05 \\
\hline & $F_{\text {is }}$ & $0.20^{* *}$ & $0.15^{* *}$ \\
\hline \multirow[t]{5}{*}{ Multilocus } & $\mathrm{N}$ & 37 & 46 \\
\hline & A & 10 & 34 (31.37) \\
\hline & $H_{o}$ & 0.66 & 0.86 \\
\hline & $H n b$ & 0.77 & 0.96 \\
\hline & $F_{\text {is }}$ & $0.15^{* *}$ & $0.10^{* *}$ \\
\hline
\end{tabular}


Table 2: Modal decomposition of the size-frequency distributions of the larval progenies from the four crosses using a combination of

690

\begin{tabular}{|c|c|c|c|c|c|c|c|c|c|c|c|c|c|c|c|c|c|c|c|c|}
\hline \multirow[b]{2}{*}{ Day } & \multirow[b]{2}{*}{ n } & \multicolumn{3}{|c|}{ HхH } & \multirow[b]{2}{*}{$\begin{array}{c}\text { Effective } \\
(\%)\end{array}$} & \multicolumn{5}{|c|}{ WxW } & \multicolumn{5}{|c|}{ WxH } & \multicolumn{5}{|c|}{$\mathbf{H} \times \mathbf{W}$} \\
\hline & & Mode & $\begin{array}{c}\text { Mean } \\
\text { size }\end{array}$ & SD & & $\mathbf{n}$ & Mode & $\begin{array}{c}\text { Mean } \\
\text { size }\end{array}$ & SD & $\begin{array}{c}\text { Effective } \\
(\%)\end{array}$ & $\mathbf{n}$ & Mode & $\begin{array}{c}\text { Mean } \\
\text { size }\end{array}$ & SD & $\begin{array}{c}\begin{array}{c}\text { Effective } \\
(\%)\end{array} \\
\end{array}$ & $\mathbf{n}$ & Mode & $\begin{array}{c}\text { Mean } \\
\text { size }\end{array}$ & SD & $\begin{array}{c}\text { Effective } \\
(\%) \\
\end{array}$ \\
\hline 3 & 356 & 1 & 94.8 & 7.2 & 100.0 & 344 & 1 & 91.3 & 5.0 & 100.0 & 394 & 1 & 94.8 & 7.1 & 100.0 & 360 & & 94.9 & 7.2 & 100.0 \\
\hline 6 & 299 & 1 & 116.4 & 12.3 & 100.0 & 308 & 1 & 115.1 & 8.0 & 100.0 & 324 & 1 & 119.3 & 8.9 & 100.0 & 330 & 1 & 117.3 & 7.2 & 100.0 \\
\hline \multirow[t]{2}{*}{8} & 284 & 1 & 133.3 & 13.4 & 38.9 & 308 & 1 & 137.1 & 11.9 & 100.0 & 318 & 1 & 140.6 & 11.2 & 100.0 & 297 & 1 & 143.8 & 11.0 & 100.0 \\
\hline & & 2 & 152.4 & 8.5 & 61.2 & & & & & & & & & & & & & & & \\
\hline \multirow[t]{2}{*}{10} & 261 & 1 & 127.3 & 14.1 & 40.0 & 298 & 1 & 146.5 & 12.7 & 100.0 & 317 & 1 & 152.9 & 11.4 & 100.0 & 276 & 1 & 151.9 & 12.8 & 100.0 \\
\hline & & 2 & 166.5 & 11.1 & 60.0 & & & & & & & & & & & & & & & \\
\hline \multirow[t]{2}{*}{13} & 233 & 1 & 138.2 & 18.1 & 28.4 & 253 & 1 & 169.6 & 15.2 & 100.0 & 282 & 1 & 174.6 & 11.9 & 100.0 & 257 & 1 & 177.7 & 16.3 & 100.0 \\
\hline & & 2 & 187.6 & 15.5 & 71.6 & & & & & & & & & & & & & & & \\
\hline \multirow[t]{3}{*}{15} & 214 & 1 & 128.5 & 12.0 & 15.9 & 253 & 1 & 133.4 & 7.5 & 2.7 & 260 & 1 & 199.1 & 17.1 & 100.0 & 217 & 1 & 210.6 & 16.9 & 100.0 \\
\hline & & 2 & 164.7 & 20.9 & 15.9 & & 2 & 190.5 & 16.1 & 97.3 & & & & & & & & & & \\
\hline & & 3 & 217.2 & 16.7 & 68.2 & & & & & & & & & & & & & & & \\
\hline \multirow[t]{3}{*}{17} & 182 & 1 & 126.1 & 12.0 & 11.5 & 244 & 1 & 180.6 & 12.4 & 14.9 & 260 & 1 & 229.2 & 24.3 & 100.0 & 217 & 1 & 240.7 & 24.1 & 100.0 \\
\hline & & 2 & 173.5 & 29.2 & 20.7 & & 2 & 223.7 & 16.9 & 85.1 & & & & & & & & & & \\
\hline & & 3 & 247.1 & 18.0 & 67.8 & & & & & & & & & & & & & & & \\
\hline
\end{tabular}

691 (n = mean number of larvae per tank / 1000) 

Figure 1: Permutation testing of the significance of the relatedness measure estimated by

693 Queller and Goodnight (rxyQG) (1989) and Lynch and Ritland (rxyLR) (1999) coefficient.

694 Arrows indicate observed values.
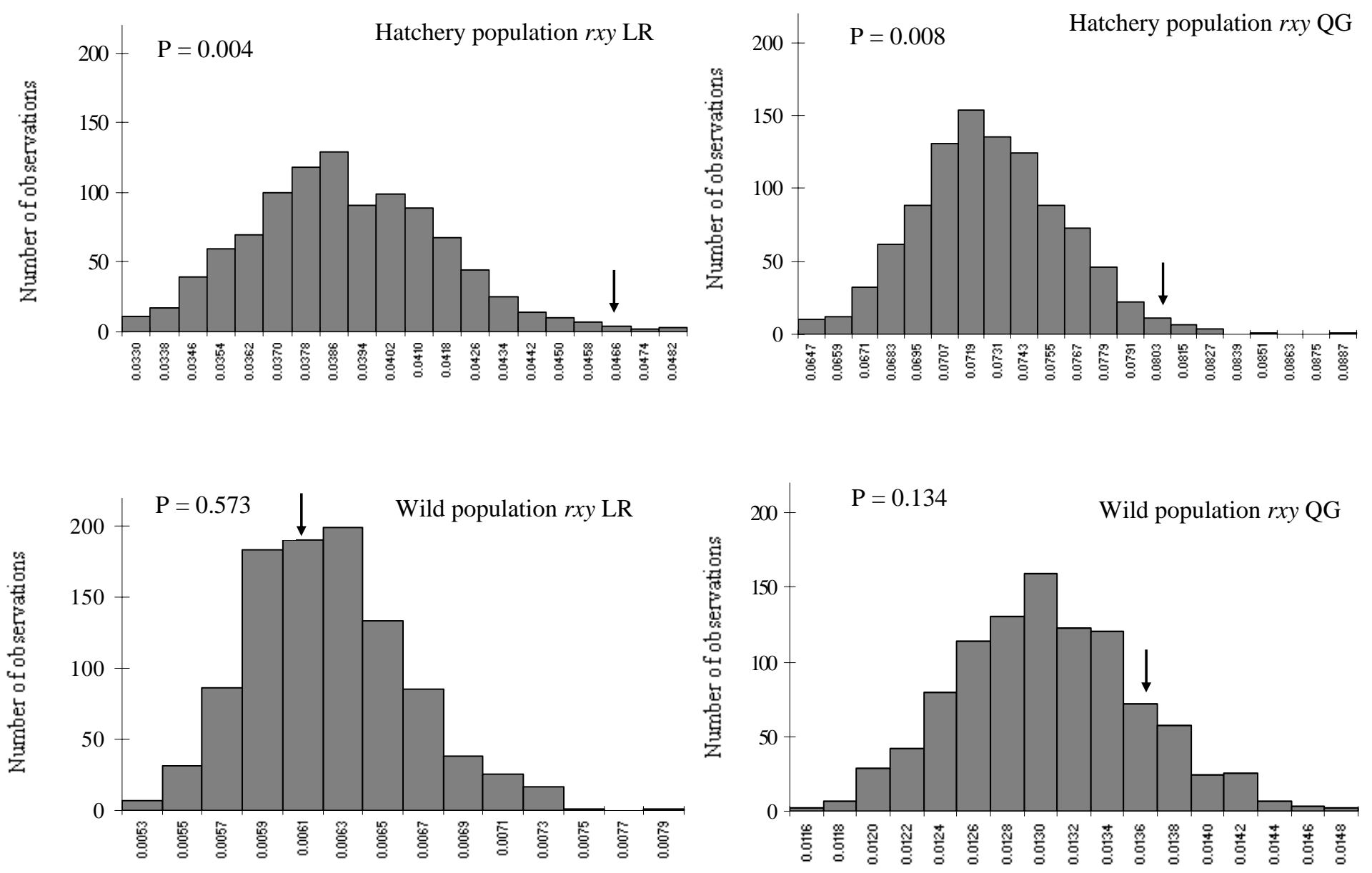

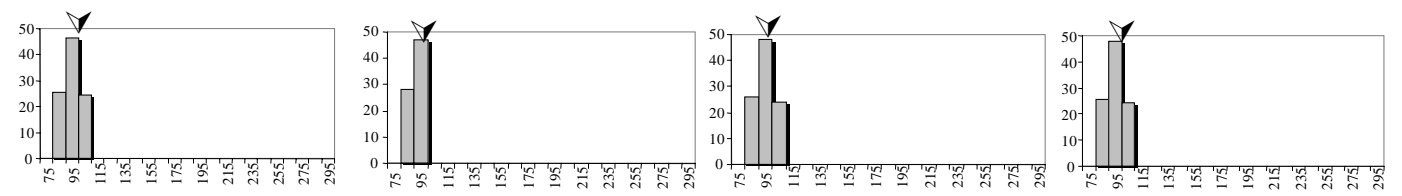

Day 6
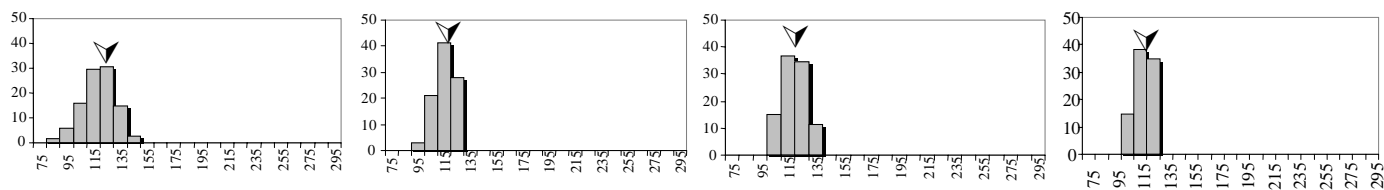

Day 8
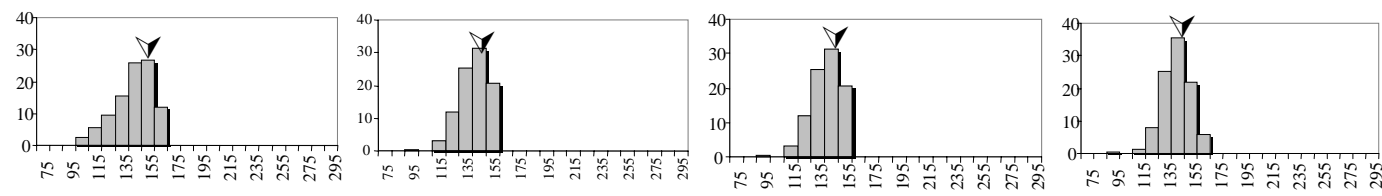

Day 10
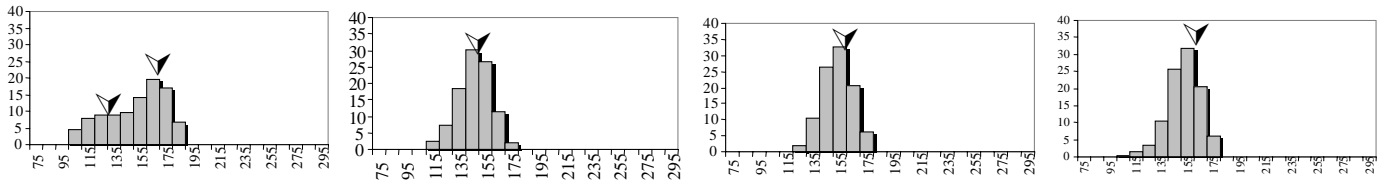

Day 13
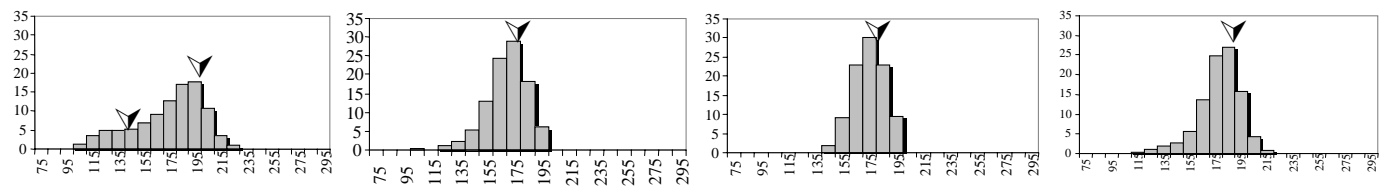

Day 15
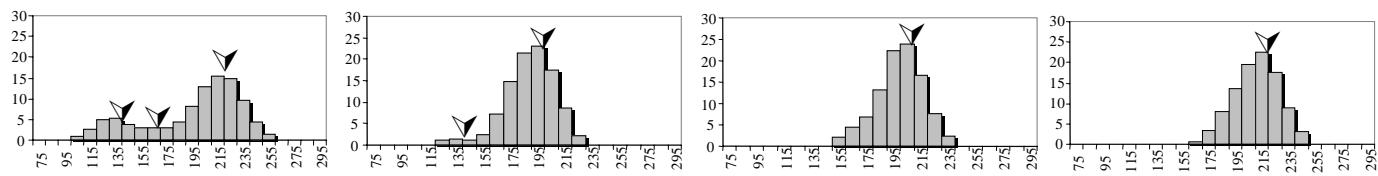

Day 17
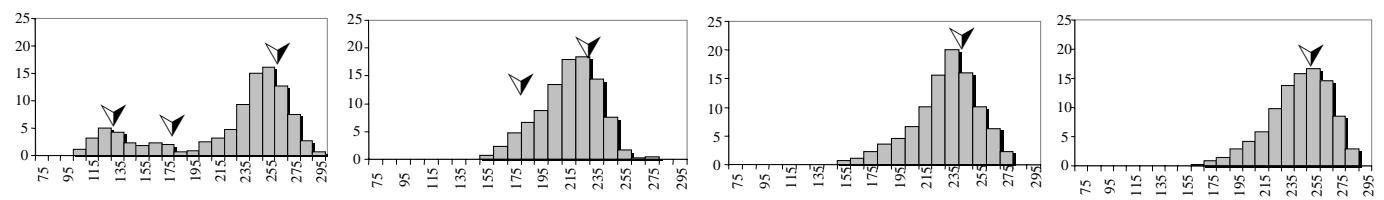

699

WxW

WxH

HxW 
Figure 3: Temporal changes in the coefficients of variation for larval size.

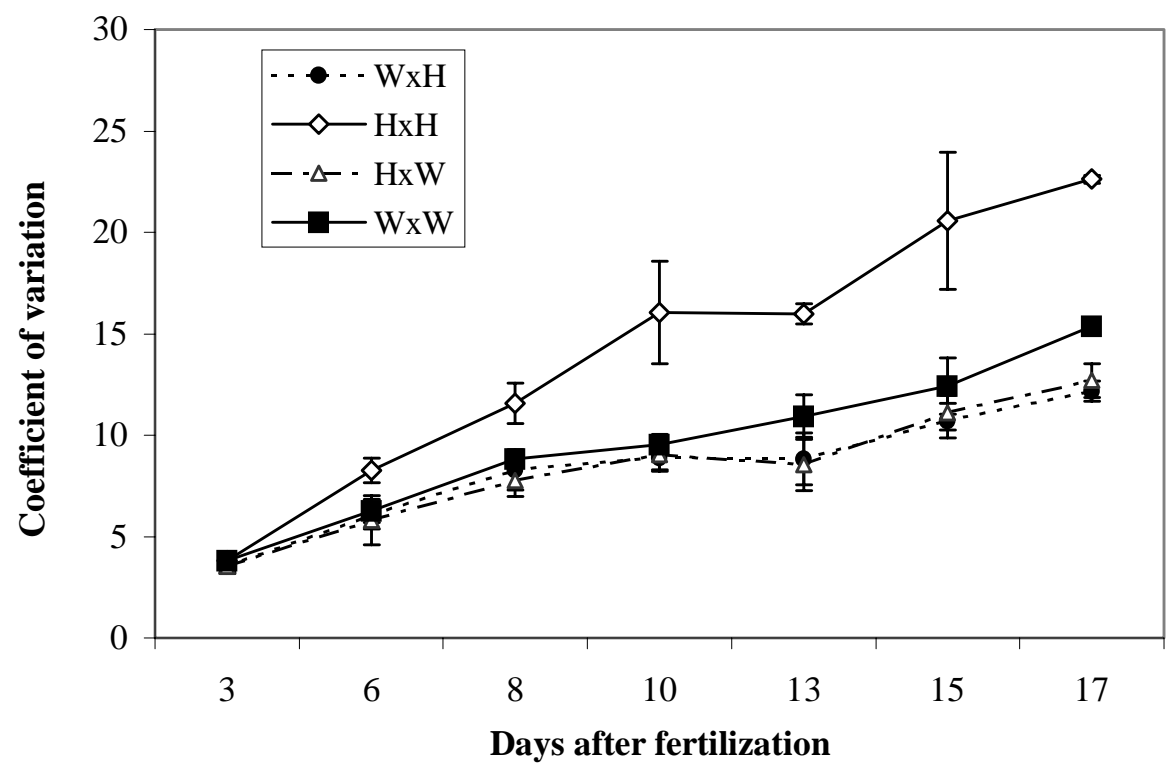


$701 \quad$ Figure 4: Mean survival of larvae from day 3 to day 20 for each cross type. No significant

702 survival was observed between crosses up to day 15 . HxH progeny showed significantly

703 lower survival than the other progenies from day 17.

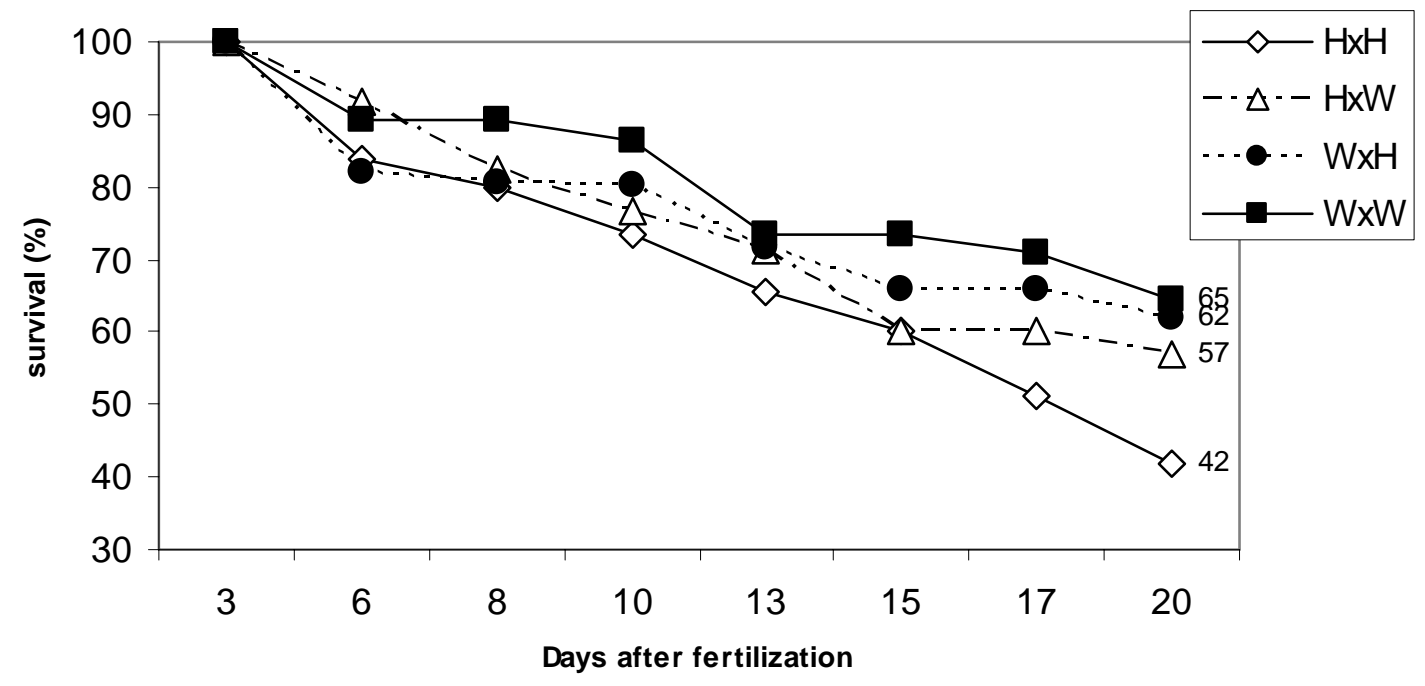


Figure 5: Temporal evolution of pediveliger larvae effectives of the four progenies.

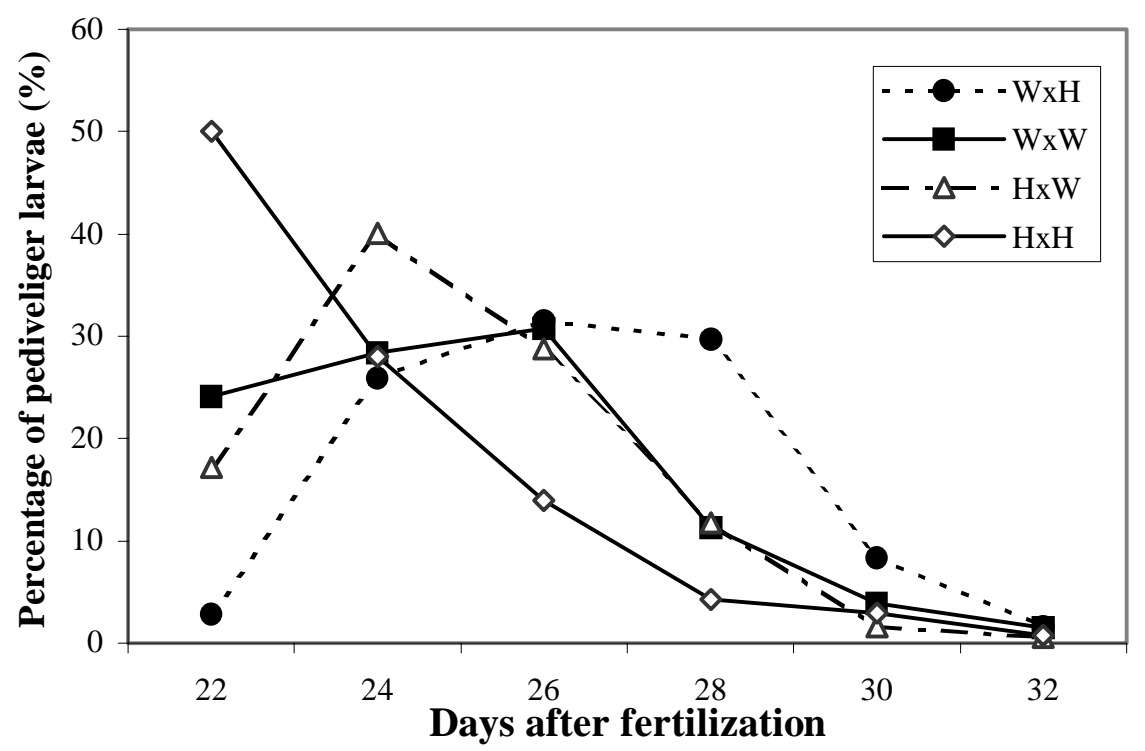

707 